\title{
Quaternary glacier development and the relationship between the climate change and tectonic uplift in the Helan Mountain
}

\author{
ZHANG Wei ${ }^{1 *}$, HE MingYue ${ }^{1}$, LI YongHua ${ }^{1}$, CUI ZhiJiu ${ }^{2}$, WANG ZhiLin ${ }^{1} \&$ YU Yang ${ }^{1}$ \\ ${ }^{1}$ College of Urban and Environment Sciences, Liaoning Normal University, Dalian 116029, China; \\ ${ }^{2}$ Department of Geography, Peking University, Beijing 100087, China
}

Received January 16, 2012; accepted April 23, 2012; published online June 17, 2012

\begin{abstract}
Isolated NE-SW stretching the Helan Mountain massif, separating the temperate grassland of the Ordos plateau from the Tenggeli Desert, is a key position of studying the glacier development in west China as well as the coupling conditions of climate change with tectonic uplift. The glacial landforms and deposits including cirques, peaks, knife-edge ridges, lateral moraines, and terminal moraines distribute above $2800 \mathrm{~m}$ a.s.l. in the middle part of the Helan Mountain. This distribution indicates that here was once glaciated during the late Quaternary. Morphology features show a clear sequence of landscape forming events took place throughout the Helan Mountain. Laboratory optically stimulated luminescence (OSL) and accelerator mass spectrometry radiocarbon dating (AMS ${ }^{14} \mathrm{C}$ ) results indicate a late history of glacial advance. Late Pleistocene glaciers in the middle part of the Helan Mountain advanced to near their positions at least four times, and the glacial sequences can be assigned as the middle stage

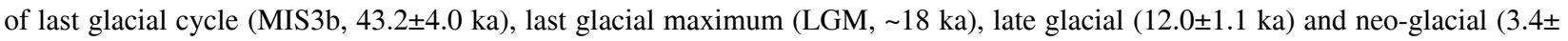
$0.3 \mathrm{ka}$ ) respectively. Adopting equilibrium line altitude $\sim 2980 \mathrm{~m}$ of last glacial maximum and the modern theoretical snowline altitude $\sim 4724 \mathrm{~m}$ as the maximum amplitudes, and the standard marine isotope curve (MIS) as the glacial equilibrium line change since the Gonghe Movement (150 ka), the relationship between the mountain altitude and glacier development is discussed herein. Compared with other environmental indexes such as the loess-paleosol and ice core, conclusions are made that glacier advances in the Helan Mountain during the late Quaternary obviously depended on the coupled control of tectonic uplift of mountain with the climate condition. It is at last glaciation that the mountain reached the altitude above snowline and coupled with the glacial climate. The glacial advances occurred in the early and middle stages of last glacial cycle after the Gonghe Movement.
\end{abstract}

Helan Mountain, last glacial cycle, tectonic uplift, equilibrium line, glaciation

Citation: Zhang W, He M Y, Li Y H, et al. Quaternary glacier development and the relationship between the climate change and tectonic uplift in the Helan Mountain. Chin Sci Bull, 2012, 57: 4491-4504, doi: 10.1007/s11434-012-5283-z

Recent years have seen increasing interest in the role that tectonic movements may play in controlling global climate, partly stemming from suggestions that uplift of the Tibetan Plateau in the late Cenozoic had a profound effect on atmospheric circulation [1]. With Pleistocene glaciations recognized as a consequence of variations in the orbit of the Earth superimposed on a long-term global cooling throughout the Cenozoic era, attention has been directed to the association of this cooling with regional elevation changes [2]. The relationship between tectonic uplift, climate change and

*Corresponding author (email: zhangweilnu@163.com) the onset of Quaternary glaciation in the Himalayas, the Tibetan Plateau, and the bordering mountains in East Asia has been documented during the last half century. It has been noticed that the glaciations in high Asia and the surrounding mountains occurred later than the high latitudes and polar region and variations deviated from the fluctuation pattern of the global ice volume [3-6]. The reason could be that the uplift history of the mighty Tibetan Plateau, which has played an important role in driving the world into glacial state during the Cenozoic, is late. Previous studies showed that the earliest typical Pleistocene glaciations in high mountains of western China are estimated to be around 
570-580 ka [7]. It was the Kunlun-Huanghe tectonic movement around 0.6-0.8 Ma that pushed the plateau surface to the height of $\sim 3500 \mathrm{~m}$ [7]. Furthermore, it was at this height that the cooling effect of the plateau became important. The orbital configuration was also changed towards the dominance of the $100 \mathrm{ka}$ cycle around the same time, which led to further cooling of the Earth. The Gonghe Movement started from around $150 \mathrm{ka}$ after the Kunlun-Huanghe Movement had a profound impact on the landforms of the Tibetan Plateau and the bordering mountains [8]. The Gonghe Movement substantially uplifted and extended the Tibetan Plateau, and made the Tibetan Plateau reach its current altitude. At the same time, many rivers on the plateau began to intensively cut down due to the uplift [8]. For example, the Yellow river incised into loess and gravel sediments and underlying bedrock by $900-1000 \mathrm{~m}$ since $150 \mathrm{ka}$. The surface uplift caused by the Gonghe Movement further promoted the development of glaciers [9,10]. The extensive glaciations in China were therefore developed when the climatic and tectonic factors were combined to make effect. That is, Pleistocene glaciations in the high Asia and the bordering mountains may be the results of coupled control of intense regional tectonic uplift and the variations in the Earth's orbit superimposed on a long-term global cooling throughout the Cenozoic era. To be specifically, tectonic uplift such as the Kunlun-Huanghe Movement and the Gonghe Movement played a major role in driving the onset of glaciations in China. In the test this hypothesis, however, the extent and timing of glaciation in the bordering mountains of the Tibetan Plateau are poorly defined owing to the lack of absolute ages.

In the past, some scholars have primarily investigated the glacial landforms and deposits around the main peak of Helan Mountain. Based on geomorphology and relative glacial deposits, they put forward different ideas of Quaternary glacial advances in this region [11-16]. However, the number and extent of glacial events that influenced the Helan Mountain have not been further studied. Moreover, the lack of dating control makes the correlation within and between regions difficult. In this paper, we review the evidence for glaciation, and present a detailed revised map of glacial landforms near the main peak of the Helan Mountain, and Optically Stimulated Luminescence (OSL) ages for moraine sequences well-preserved in the northwest slope of the Helan Mountain. According to the OSL, accelerator mass spectrometry radiocarbon (AMS ${ }^{14} \mathrm{C}$ ) dating results of glacial deposits, loess, soil developed in the upper part of the moraines and the organic compound in the glacial erosive lake, we establish a preliminary chronological glacial succession for the last glacial cycle. Finally, we discuss the timing of the glacier advances and the relationship between the tectonic uplift and climate change in this area. The study areas and dating results are shown in Figure 1 and Tables 1 and 2.

\section{Regional settings}

The Helan Mountain is an isolated NE-SW stretching mountain massif, approximately $150 \mathrm{~km}$ long and 20-60 km wide, separating the temperate grassland of the Ordos Plateau from the Tenggeli Desert. It is situated between $38^{\circ}-39^{\circ}$ $30^{\prime} \mathrm{N}$ and $105^{\circ} 11^{\prime}-106^{\circ} 45^{\prime} \mathrm{E}$ at the transition zone from semiarid to arid environments and is surrounded by the Ningxia plain in the east, Wulanbuhe Desert in the north,

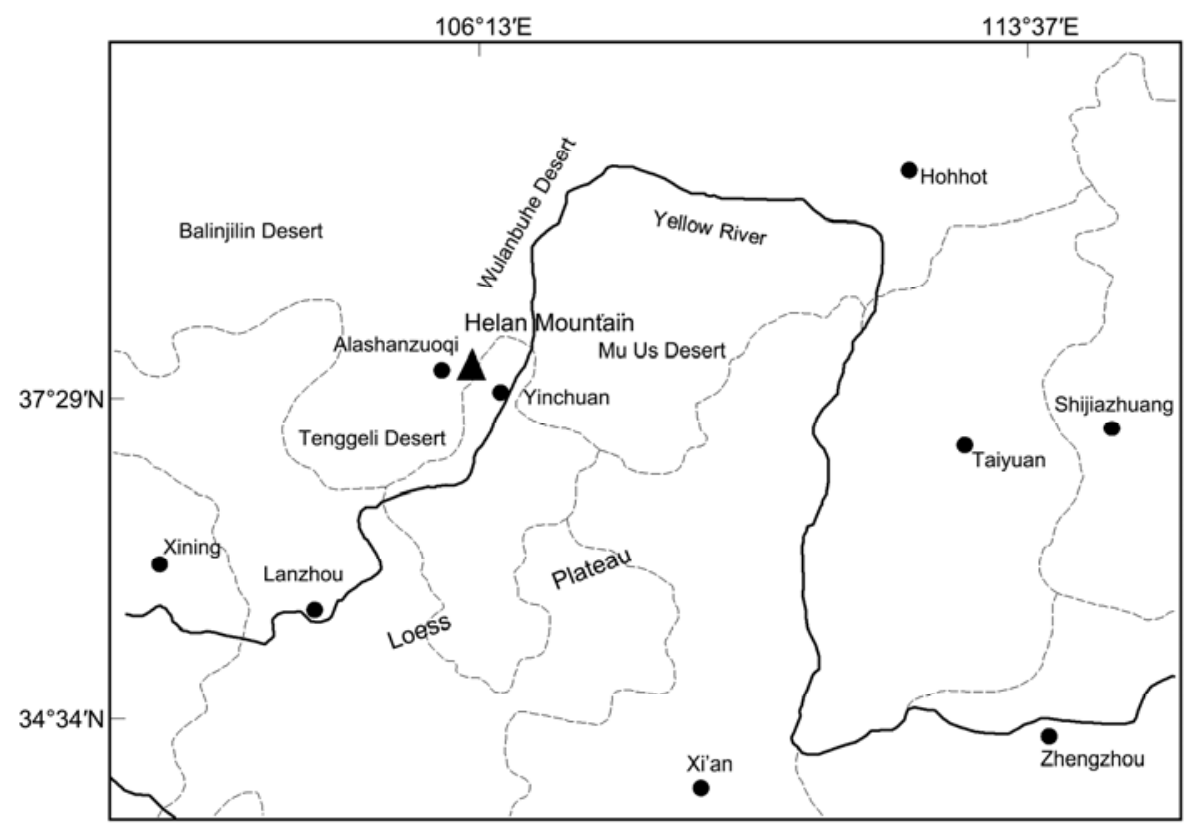

Figure 1 The location of the study area. 
Table 1 AMS ${ }^{14} \mathrm{C}$ dating results in Helan Mountain ${ }^{\text {a) }}$

\begin{tabular}{cccc}
\hline LAB number & Sample & Number & ${ }^{14}$ C dating (a BP) \\
\hline BA091529 & soil & $200910 C-1$ & $3900 \pm 35$ \\
BA091530 & soil & $200910 C-2$ & $640 \pm 30$ \\
BA091531 & soil & $200910 C-3$ & $1100 \pm 35$ \\
\hline
\end{tabular}

a) The half recession time of the ${ }^{14} \mathrm{C}$ that we use is 5568 years and $\mathrm{BP}$ is the period which before 1950 .

Tenggli Desert in the west and Loess plateau in the south.

According to the geomorphological characteristics, the Helan Mountain is usually divided into three parts from north to south. The elevation of most peaks in the middle part is higher than $3000 \mathrm{~m}$ with a main peak reaching to $3556 \mathrm{~m}$. The divide tends to the eastern side and both slopes are obviously asymmetric. The west slope is gentle while the east slope is steep [11]. The exposed stratum in the Helan Mountain formed from the Paleozoic to Mesozoic era [17]. Most of the study area consists of quart sandstones and conglomerates of Triassic and Jurassic [12]. These clastics are consolidated, so that the rock is extraordinarily tough. The Helan Mountain Meteorological Station (2901 m a.s.1.) records the annual mean air temperature of $-0.8^{\circ} \mathrm{C}$ and a mean precipitation of about $430 \mathrm{~mm}$ annually. The precipitation mainly concentrates on the summer and account for about $62 \%$ from June to September, while the temperature gradient in the west slope $\left(0.55^{\circ} \mathrm{C} / 100 \mathrm{~m}\right)$ is slightly larger than the east slope $\left(0.52^{\circ} \mathrm{C} / 100 \mathrm{~m}\right)$ [18]. There are no modern glaciers, but some snow drifts can be preserved in the shade depressions at the highest elevations all the year. The vegetation in the Helan Mountain varies with altitudes because of the different topography, soil and geology in the west and east slopes. There is a clearly vertical zonality in the west slope-mountainous grassland, desert grassland zone (1400-1600 m), sparse forest grassland zone (1600$1900 \mathrm{~m})$, mountainous coniferous forest zone (1900-3100 m) and sub-alpine shrub meadow zone (3100-3556 m).

\section{Materials and methods}

\subsection{Field investigation}

The field study is based on the conventional geomorphologic mapping including landform and sediment analyses, together with air photos and map interpretations. Landforms are mapped along the west slope near the main peak of Aobaogeda at a scale of 1:50000, and at 1:10000 for selected areas. The morphology and landforms are described according to location, geometry, size, and composition, which is useful to distinguish between the glacial and the other origins of typical landforms and sediments associated with reference localities [19-23]. A global positioning system (GPS) is used to determine locations and altitudes. Using the multi-parameter relative age methods, we carefully

Table 2 Optically Stimulated Luminescence dating results of the fine quartz grain $(4-11 \mu \mathrm{m})$ using the SMAR method

\begin{tabular}{|c|c|c|c|c|c|c|c|c|c|c|c|}
\hline Number & Test number & Position & $\begin{array}{l}\text { Depth } \\
(\mathrm{m})\end{array}$ & $\begin{array}{l}\text { Elevation } \\
\text { (m) }\end{array}$ & Sample & $\begin{array}{c}\text { Count rate } \\
\text { of } \alpha \\
\text { (Counts/ks) }\end{array}$ & $\mathrm{K}(\%)$ & $\begin{array}{c}\text { Water } \\
\text { content } \\
(\%)\end{array}$ & $\begin{array}{c}\text { Dose rate } \\
(\mathrm{Gy} / \mathrm{ka})\end{array}$ & $\begin{array}{c}D_{\mathrm{e}} \\
(\mathrm{Gy})\end{array}$ & $\begin{array}{l}\text { Dating } \\
\text { (ka) }\end{array}$ \\
\hline 0910OSLG-1 & LEDL10-250 & $\begin{array}{l}38^{\circ} 53^{\prime} 53.4^{\prime \prime} \mathrm{N}, \\
105^{\circ} 57^{\prime} 04.3^{\prime \prime} \mathrm{E}\end{array}$ & 0.85 & 2890 & loess & $12.2 \pm 0.3$ & 2.08 & 4 & $5.0 \pm 0.2$ & $32.5 \pm 2.9$ & $6.5 \pm 0.6$ \\
\hline 0910OSLG-3 & LEDL10-252 & $\begin{array}{l}38^{\circ} 53^{\prime} 46.8^{\prime \prime} \mathrm{N} \\
105^{\circ} 57^{\prime} 07.8^{\prime \prime} \mathrm{E}\end{array}$ & 0.53 & 2860 & silttil & $10.6 \pm 0.4$ & 2.21 & 5 & $4.8 \pm 0.2$ & $57.5 \pm 4.8$ & $12.0 \pm 1.1$ \\
\hline 0910OSLG-4 & LEDL10-253 & $\begin{array}{l}38^{\circ} 53^{\prime} 38.9^{\prime \prime} \mathrm{N} \\
105^{\circ} 57^{\prime} 03.3^{\prime \prime} \mathrm{E}\end{array}$ & 0.5 & 2820 & silttil & $10.4 \pm 0.3$ & 2.21 & 19 & $4.6 \pm 0.2$ & $4.0 \pm 0.2$ & $0.9 \pm 0.1$ \\
\hline 0910OSLG-5 & LEDL10-254 & $\begin{array}{l}38^{\circ} 53^{\prime} 38.9^{\prime \prime} \mathrm{N} \\
105^{\circ} 57^{\prime} 03.3^{\prime \prime} \mathrm{E}\end{array}$ & 0.5 & 2820 & silttil & $10.0 \pm 0.3$ & 2.12 & 23 & $4.3 \pm 0.2$ & $3.7 \pm 0.2$ & $0.9 \pm 0.1$ \\
\hline 0910OSLG-6 & LEDL10-255 & $\begin{array}{l}38^{\circ} 49^{\prime} 08.2^{\prime \prime} \mathrm{N} \\
105^{\circ} 55^{\prime} 43.4^{\prime \prime} \mathrm{E}\end{array}$ & 1 & 3041 & silttil & $11.3 \pm 0.3$ & 2.33 & 3 & $5.1 \pm 0.2$ & $17.3 \pm 1.3$ & $3.4 \pm 0.3$ \\
\hline 0910OSLG-7 & LEDL10-256 & $\begin{array}{l}38^{\circ} 49^{\prime} 07.7^{\prime \prime} \mathrm{N} \\
105^{\circ} 55^{\prime} 44.1^{\prime \prime} \mathrm{E}\end{array}$ & 0.7 & 3040 & silttil & $7.7 \pm 0.2$ & 2.27 & 5 & $4.2 \pm 0.2$ & $7.0 \pm 0.3$ & $1.7 \pm 0.1$ \\
\hline 0910OSLG-8 & LEDL10-257 & $\begin{array}{l}38^{\circ} 49^{\prime} 04.9^{\prime \prime} \mathrm{N}, \\
105^{\circ} 55^{\prime} 44.4^{\prime \prime} \mathrm{E}\end{array}$ & 0.6 & 3030 & silttil & $5.2 \pm 0.2$ & 2.31 & 6 & $3.7 \pm 0.2$ & $159.8 \pm 14.4$ & $43.2 \pm 4.0$ \\
\hline 0910OSLG-9 & LEDL10-258 & $\begin{array}{l}38^{\circ} 49^{\prime} 04.9^{\prime \prime} \mathrm{N} \\
105^{\circ} 55^{\prime} 44.4^{\prime \prime} \mathrm{E}\end{array}$ & 0.6 & 3030 & silttil & $10.1 \pm 0.2$ & 2.27 & 1 & $4.8 \pm 0.2$ & $36.1 \pm 4.1$ & $7.5 \pm 0.9$ \\
\hline 0910OSLG-10 & LEDL10-259 & $\begin{array}{l}38^{\circ} 49^{\prime} 10.2^{\prime \prime} \mathrm{N} \\
105^{\circ} 55^{\prime} 33.7^{\prime \prime} \mathrm{E}\end{array}$ & 0.6 & 2990 & silttil & $6.9 \pm 0.1$ & 2.06 & 35 & $3.2 \pm 0.2$ & $8.3 \pm 0.8$ & $2.6 \pm 0.3$ \\
\hline 0910OSLG-12 & LEDL10-261 & $\begin{array}{l}38^{\circ} 49^{\prime} 22.5^{\prime \prime} \mathrm{N} \\
105^{\circ} 55^{\prime} 28.1^{\prime \prime} \mathrm{E}\end{array}$ & 0.5 & 3020 & loess & $10.0 \pm 0.2$ & 2.07 & 5 & $4.5 \pm 0.2$ & $42.2 \pm 6.0$ & $9.3 \pm 1.4$ \\
\hline 0910OSLL-1 & LEDL10-262 & $\begin{array}{l}38^{\circ} 53^{\prime} 54.2^{\prime \prime} \mathrm{N} \\
105^{\circ} 57^{\prime} 07.6^{\prime \prime} \mathrm{E}\end{array}$ & 0.7 & 2890 & loess & $12.1 \pm 0.3$ & 2.2 & 6 & $5.1 \pm 0.2$ & $15.2 \pm 1.2$ & $3.0 \pm 0.3$ \\
\hline 0910OSLL-2 & LEDL10-263 & $\begin{array}{l}38^{\circ} 53^{\prime} 51.9^{\prime \prime} \mathrm{N} \\
105^{\circ} 57^{\prime} 05.7^{\prime \prime} \mathrm{E}\end{array}$ & 0.63 & 2880 & loess & $13.1 \pm 0.4$ & 1.8 & 14 & $4.7 \pm 0.2$ & $20.1 \pm 3.1$ & $4.3 \pm 0.7$ \\
\hline
\end{tabular}

a) The number of coefficient $\alpha$ is $0.04 \pm 0.02$. The error rate is $3 \%$, the error rate of the content of $\mathrm{K}$ is $5 \%$, moisture content error is $4 \%$, the error rate of the Cosmic rays is $5 \%$, the error rate of the equivalent dose $\left(D_{\mathrm{e}}\right)$ is $6 \%-7 \%$ and the error rate of environmental measuring is $12 \%$. Environmental measuring is based on the contribution of the coefficient $\alpha$, element $\mathrm{K}$, water and cosmic rays. 
identified the glacial and non-glacial diamicts in consideration of the widespread mass movements and fluvial deposits in this region. We mainly focused on definite evidence for glacial transport such as striated boulders, polished and erratic boulders, and glacial erosive and depositional landform associations. Among the relative age criteria applied to differentiate and correlate glacial deposits, the most useful ways are the degrees of boulder weathering, soil development, distal slope angles of terminal moraines, and topographic positions of the terminal and lateral moraines. Sites are chosen for the collection of samples for OSL dating according to the relative chronologies (Figure 2). The fine grain glacial matrix of the lateral and terminal moraines and its covered loess in Chagou and Zhaobeishangou valleys are selected to carry out the OSL dating. The OSL samples are obtained by hammering steel tubes, $25 \mathrm{~cm}$ long and $4 \mathrm{~cm}$ in
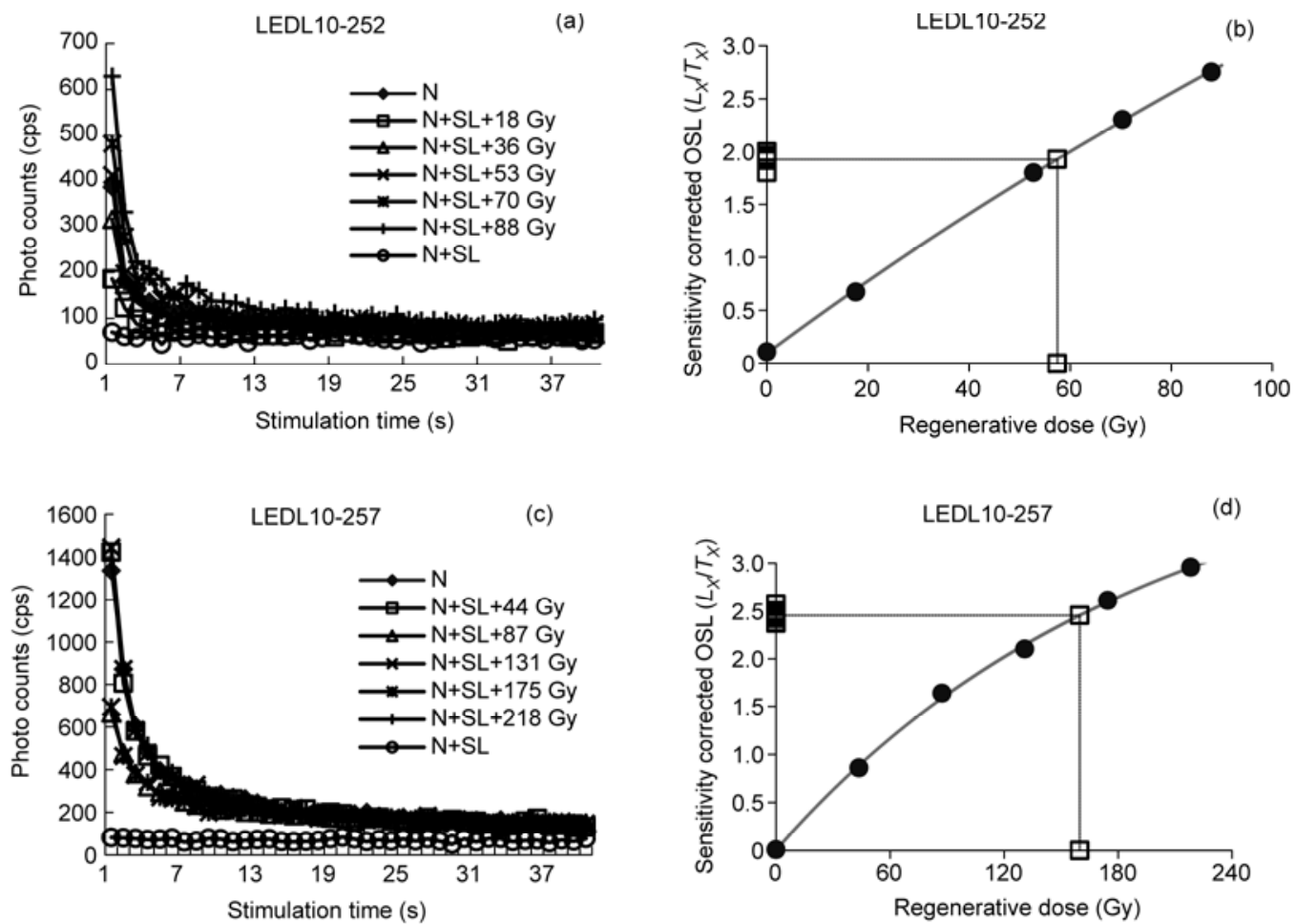

OSL dating provides a way of dating glacial deposits directly, especially those devoid of organic material suitable for radiocarbon dating. Luminescence dating have led to increasing application of the technique to sediments from a wide range of depositional environment [24,25]. The OSL dates presented in this study are conducted at State Key in the cirque, and soil in the upper part of the moraines to carry out the ${ }^{14} \mathrm{C}$ dating. Sample sites are shown in Figure 3.

\subsection{Dating}

diameter with one side sealed, into clean sections. Once taken out, the other side of each steel tube is sealed and placed in light-tight sampling bags. All the samples remained sealed until they are opened in the laboratory. Meanwhile, we choose the abundant organic matter deposit

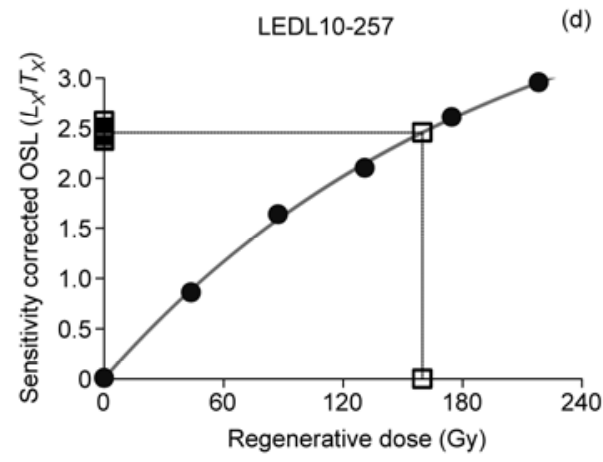

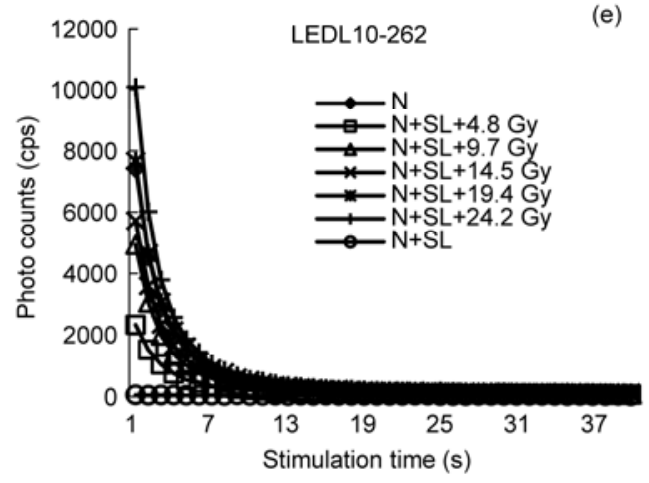

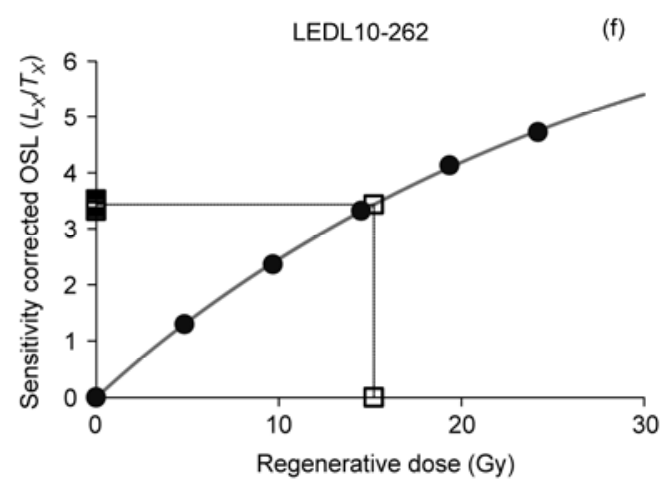

Figure 2 Representative data of $D_{\mathrm{e}}$ determination by the sensitivity-corrected MAR protocol. (a), (c) and (e) Decay curves of natural and regeneration dose OSL intensity $\left(L_{i}\right)$; (b), (d) and (f) the corrected OSL $\left(L_{i} / T_{i}\right)$ dose-response curves and $D_{\mathrm{e}}$ determination. 
Laboratory of Earthquake Dynamics Institute of Geology, China Earthquake Administration, using the Sensitivitycorrected Multiple Aliquot Regenerative-Dose (SMAR) method developed by Wang et al. [26] and Lu et al. [27] for the fine-grained $(4-11 \mu \mathrm{m})$ quartz fractions. Sample preparation and the dating are based on the procedures of $\mathrm{Lu}$ et al. [27]. All measurements are taken using a Daybreak 1100A automated OSL reader equipped with a combined blue $(470 \pm 5 \mathrm{~nm})$ or infrared $(880 \pm 80 \mathrm{~nm})$ LED unit, and a $90 \mathrm{Sr} /$ $90 \mathrm{Y}$ beta source for irradiations. All luminescence measurements are taken at $125^{\circ} \mathrm{C}$ for $50 \mathrm{~s}$ with blue stimulation intensities at $\sim 40 \mathrm{~mW} / \mathrm{cm}^{2}$. Luminescence emissions are detected by an EMI QA9235 photomultiplier tube (PMT) and two U-340 filters (2.5 and $4.5 \mathrm{~nm}$ ). For equivalent dose $\left(D_{\mathrm{e}}\right)$ calculation, the first 1-s integral of the OSL decay curve was used after subtracting that of the last $1 \mathrm{~s}$. Bleaching is provided by a solar simulator (SOL2).

(i) Equivalent dose determination. For obtaining relatively precise OSL ages, the more suitable OSL methods are the Single Aliquot Regenerative-dose (SAR) approaches for fine-grained quartz [26]. The SAR method has successfully settled the main problem of sensitivity change. However, this method must use a repeated single aliquot to establish the OSL growth curves, and this may lead to underestimation of the $D_{\mathrm{e}}$ value due to the accumulation of OSL signal during the repeated measurements. Therefore, Lu et al. [27] put forward a sensitivity-corrected Multiple Aliquot Regenerative-dose (SMAR) method. In this method, after each natural and regenerative OSL $\left(L_{X}\right)$ measurement, a test dose OSL response $\left(T_{X}\right)$ is measured to compensate for differences in luminescence production during the measurement of the quartz OSL signals. The growth of the normalized luminescence $\left(L_{X} / T_{X}\right)$ for the regeneration doses is used to determine the De value for the natural value $\left(L_{N} / T_{N}\right)$. On the basis of the fine-grained quartz OSL-age estimates for 23 loess samples, Lu et al. compared the De values using the MAR with the SAR protocol in the same measurement conditions and concluded that the sensitivity-corrected MAR protocol and the relative experimental conditions are suitable. Some uncertainty exists using the OSL dating method to determine the ages of glacial deposits such as the weak signal, thermal transfer and incomplete exposure, but the SMAR method can primarily solve the disadvantage factors of sensitivity change, thermal transfer and data scatter. The equivalent dose decay curves (Figure 2(a),(c),(e)) show the lower OSL intensity $\left(L_{i}\right)$ compared with the loess sample. Among them, the signal of LED-252 is the weakest, but the corrected OSL $\left(L_{i} / T_{i}\right)$ dose-response curve indicate that the natural and regeneration dose $(\mathrm{N}+\mathrm{SL})$ of this sample tends to zero. Similarities of other samples show that the thermal transfer is essentially removed, so we believe that the dating results are reliable.

(ii) Environmental dose rate determination. The dose rate, which is an estimate of radioactivity of sediment surrounding the sample during the burial period, must be de- termined correctly in OSL dating. Most radiations are from the decay of varying amounts of ${ }^{238} \mathrm{U},{ }^{232} \mathrm{Th}$ and ${ }^{40} \mathrm{~K}$ content of mineral grains and the contribution of some cosmic rays. In this study, the $\mathrm{U}$ and $\mathrm{Th}$ contents are determined by alpha counting method, which assumes secular equilibrium in decay series. The ${ }^{40} \mathrm{~K}$ level is gained from the $\mathrm{K}$ content measured by flame photometry [28]. Dose rate of samples is calculated according to the conversion relationship presented by Atiken [29] between the contents of ${ }^{238} \mathrm{U},{ }^{232} \mathrm{Th}$, and

${ }^{40} \mathrm{~K}$ and the receiving dose rate of quartz and feldspar. The measured water content is adopted to calculate the environmental dose rate with the correction of saturated water content and the influence of the contribution of cosmic ray.

\section{Glacial geomorphological features and chronologies}

Glacial landforms and their distribution are investigated in detail in the middle part of the Helan Mountain. Clear glacial landforms and deposits, such as cirques, horns and knife-edged ridges, thresholds, terminal moraines, and lateral moraines, are distributed above $2800 \mathrm{~m}$ of the west slope near the main peak of Aobaogeda (Figures 1 and 3). We have defined the limit of glaciation by the outmost moraines, which bound areas of glacial erosion and deposits of till. The maps show a preliminary area of glacier cover about $68.75 \mathrm{~km}^{2}$.

\subsection{Glacial erosive landforms}

(i) Cirques and threshold. Definite cirques develop in the east and west sides along the main ridge of the Helan Mountain. According to their shapes and altitudes, the cirques can be divided into two groups. The well-developed concavities with semicircular headwalls of the first group are higher than $3000 \mathrm{~m}$ and mainly distribute in the valley heads of Cha in the northwestern Aobaogeda (3556 m) and of the Zhaobeishan in the northern Aobao peak (3554 m). This group includes Lujiatai cirque, Yangjiatang cirque, and $Z_{1}, Z_{2}, Z_{3}, 300-1300 \mathrm{~m}$ long, 250-900 $\mathrm{m}$ wide and 200$450 \mathrm{~m}$ deep. The semicircular head and sidewalls show gradients between 20 and 35 degrees. Among them, the Lujiatai cirque is the most typical armchair depression with slightly Swamp. The cirque is $1300 \mathrm{~m}$ long and $700 \mathrm{~m}$ wide, and its headwall has already been reduced due to later frost weathering. The lower part is over deepened, while the upper part is fused with the slope. The morphology of this cirque was examined by applying the flatness index of Derbyshire and Evans. This index shows the ratio between headwall to threshold length (a) and depth taken normal to the $\mathrm{a}-\mathrm{b}$ plane of cirque (c) in the form a/2c. According to this method, we calculated the flatness index is 1.81 , which fits in with the glacial feature. Altitude of this cirque floor $(3040 \mathrm{~m})$ is the same as that of Yangjiatang (Figure 4) and indicates the past 


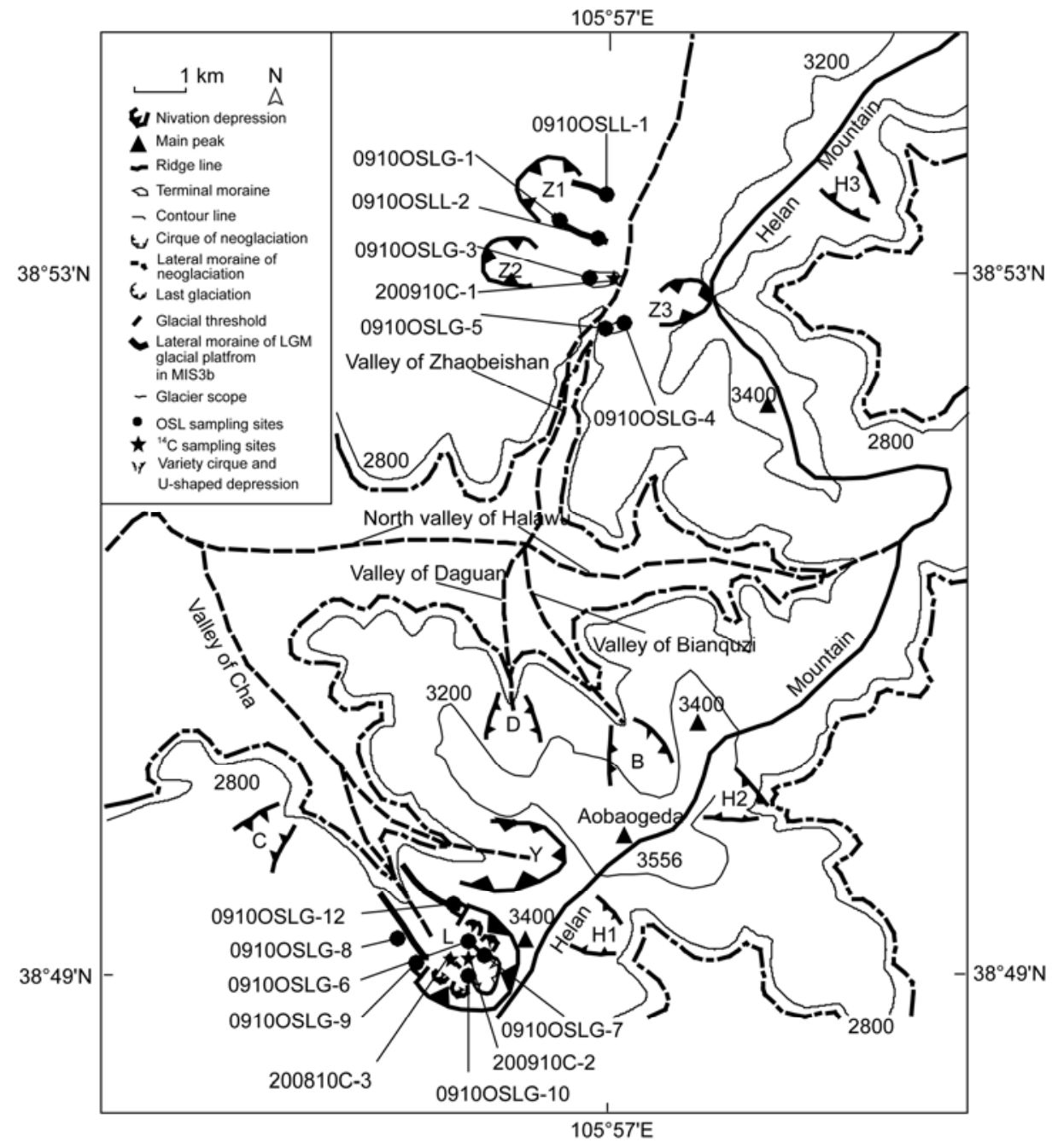

Figure 3 The glacial landforms of the summit area of Helan Mountain.

equilibrium lime could be 3000-3100 m. In addition, a parasitism cirque preserves in the back wall of Lujiatai cirque and its lower part has already entered into the cirque floor. Five different shape depressions develop around the sidewall of Lujiatai cirque. However, the flatness indexes are obviously different from the typical cirque, so we concluded that these depressions could be undergone nival or hanging glacial processes. One clear $\sim 15 \mathrm{~m}$ high threshold stretching from east to west exits at the outlet of Lujiatai cirque and has been cut apart by later glacial or fluvial action. The equal $\sim 40$-m-long remnants in both sides of this threshold only connect with the foot of mountain.

The second group cirques and U shaped depressions, represented by the Daguangou and Bianquzigou cirques, distribute on the altitudes between 2800 and $3300 \mathrm{~m}$. These cirques and depressions comprise tapering triangular hollows without any headwall and are comparatively over deepening. The erosive features are delineated by marginal discharge ravines and show straight, sometimes convex transverse and longitudinal profiles. The lower parts of them are covered with block masses. Compared with the first group, the gentle cirque slope gradients are usually between $20^{\circ}$ and $25^{\circ}$. Due to the frost weathering, the cirque headwall usually develop the sharp angle and single lithologic (sandstone and conglomerate) strip stone river extending down to the lower valley. These cirques with wide bottom hollows are called as the varieties of cirques developed in a slope facet without headwall and are interpreted as relics of small hanging glaciers or outlet from small plateau ice sheets close to the snowline. Like those of Qilanshan, the variety cirques provide another evidence that here was once glaciated during the Pleistocene. The mechanism of this kind of cirques is that the glaciers occupying these concavities are below the pressure melting point throughout so that they are frozen to their beds, move entirely by plastic deformation and shear with a low production of moraine material (Figure 5).

(ii) Horn and knife-edged ridge. The main peak Aobaogeda $(3556 \mathrm{~m})$ is an obvious horn caused by head-ward erosion from different direction of the surrounding cirque 

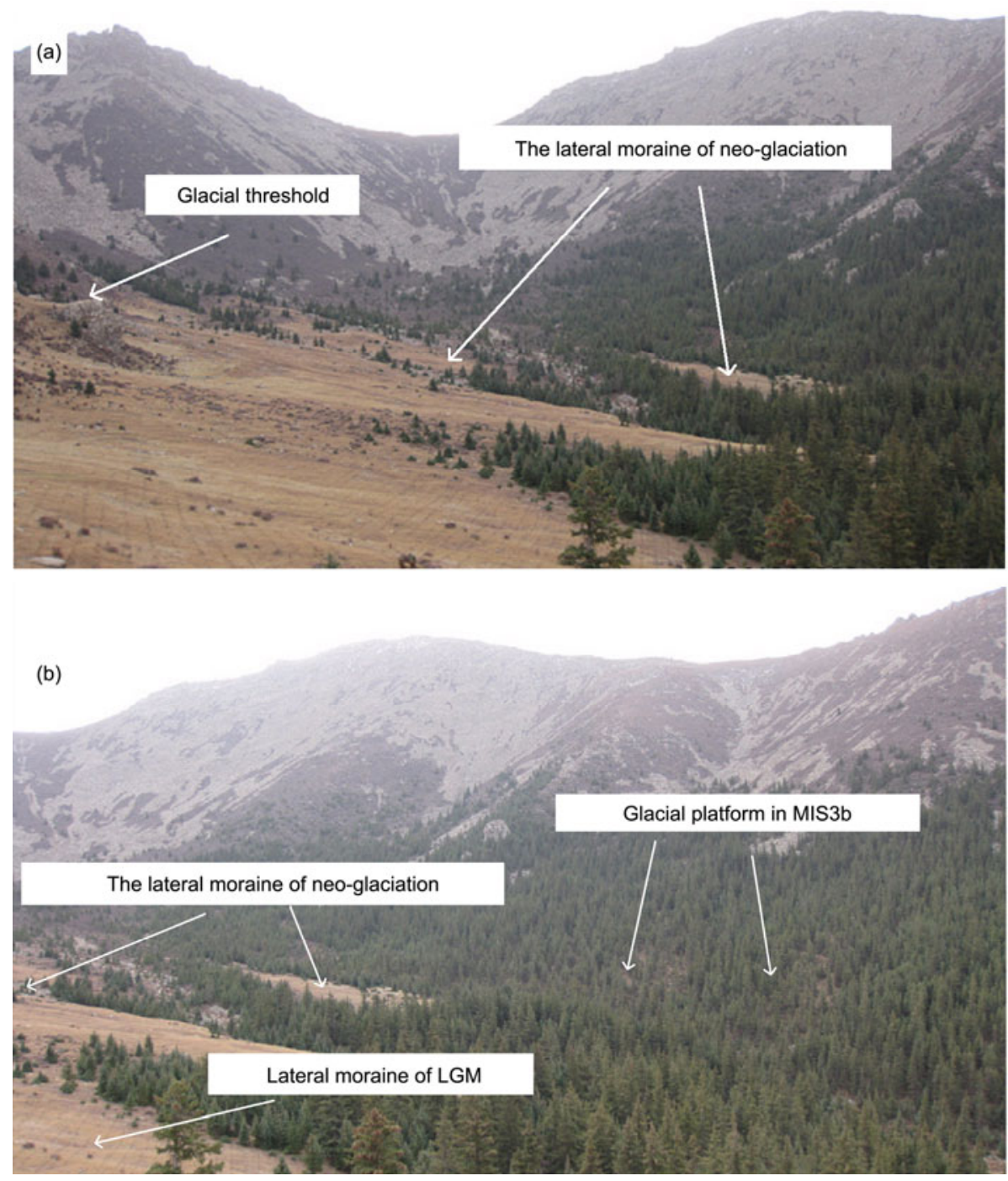

Figure 4 Glacial erosive and sediment geomorphology in the cirque of Lujiatai. (a) The glacial threshold, the lateral moraine of neo-glaciation and the sub-cirque in the back wall; (b) lateral moraine of LGM and the glacial platform in MIS3b inside the same cirque.

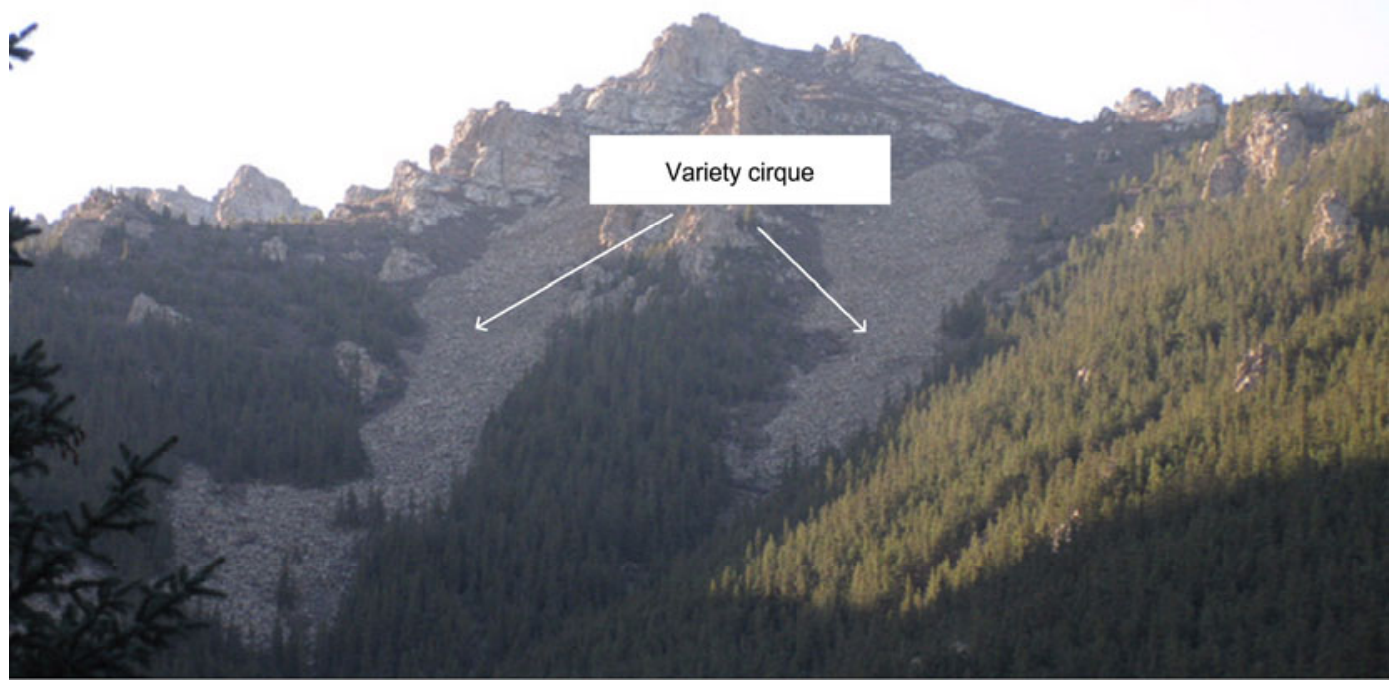

Figure 5 The variety cirque in the valley head of Daguangou and Bianquzigou. 
glaciers. However, the sandstones making up the main peak are slightly broken due to the long term freezing and thawing. The typical knife-edged ridges distribute in an altitude of 3400-3500 m between the Chagou and Bianquzigou cirques (Figure 6). Furthermore, the relatively complete ridges not only distribute between Daguangou and Bianquzigou cirques, but also distribute between the Lujiatai and Yangjiatang cirques. In addition, the typical periglacial tors are preserved in the east and west sides of the main peak.

\subsection{Glacial depositional landforms}

Lateral, terminal moraines and moraine platforms mainly distribute in the valley heads of Chagou and Zhaobeishangou with lower limit around $2800 \mathrm{~m}$. The glacial accumulated geomorphologies show the different glacial stages in this district. The OSL and AMS ${ }^{14} \mathrm{C}$ dating results indicate the late history of glacial advance. Late Pleistocene glaciers in the middle part of the Helan Mountain advanced to near their positions at least four times, and the glacial sequences can be assigned as the middle stage of last glacial cycle (MIS3), last glacial maximum (LGM), late glacial and neo-glacial respectively (Figure 7).

(i) Neoglacial glaciers advance. The moraines distribute above $3000 \mathrm{~m}$ in the valley heads of both Chagou and Zahobeishangou. Two lateral moraines about 2-3 m wide, $500 \mathrm{~m}$ long and $6 \mathrm{~m}$ high are persevered inside the Lujiatai cirque. The trailing edge of the lateral moraines connects with the parasitism cirque developed on the back wall of Lujiatai cirque. These indicate that the moraines are products of the hanging glaciers flowing into the early cirque floor. The profiles of the bare moraines show that the deposits are composed of new, angular, poorly sorted and non-stratified gravels. The components of the striated gravels are mainly sandstone and conglomerate, and the matrix accounts for only $10 \%$. According to the fresh degree and the structures of the deposits, the time of these lateral moraines is relatively short. The OSL dates collected from the matrixes in the east lateral moraine are $3.4 \pm 0.3 \mathrm{ka}$ and $1.7 \pm$ $0.1 \mathrm{ka}$, while the age in the west lateral moraine is $2.6 \pm 0.3 \mathrm{ka}$. Moreover, the AMS ${ }^{14} \mathrm{C}$ age of soil at the top of the west moraine is $1100 \pm 35$ a BP. Adopting the AMS ${ }^{14} \mathrm{C}$ dating method, we dated the organic matter developed in the cirque lake between these two lateral moraines and obtained an age of $640 \pm 30$ a BP. All dates above mentioned definitely indicate this glacial advance took place during the neoglaciation. This glacial advance also happened in the valley head of Zhaobeishangou above $3100-3300 \mathrm{~m}$. The partly destroyed glacial deposits distribute in the cirques of $Z_{1}$ and $Z_{2}$, but the morphology is not typical as that in Lujiatai cirque.

(ii) Late glacial advance. Two terminal moraines near the loess beam stretching from east to west are located from $2900 \mathrm{~m}$ along the slope down to $2800 \mathrm{~m}$ in the valley head of Zhaobeishangou. The terminal moraines which have

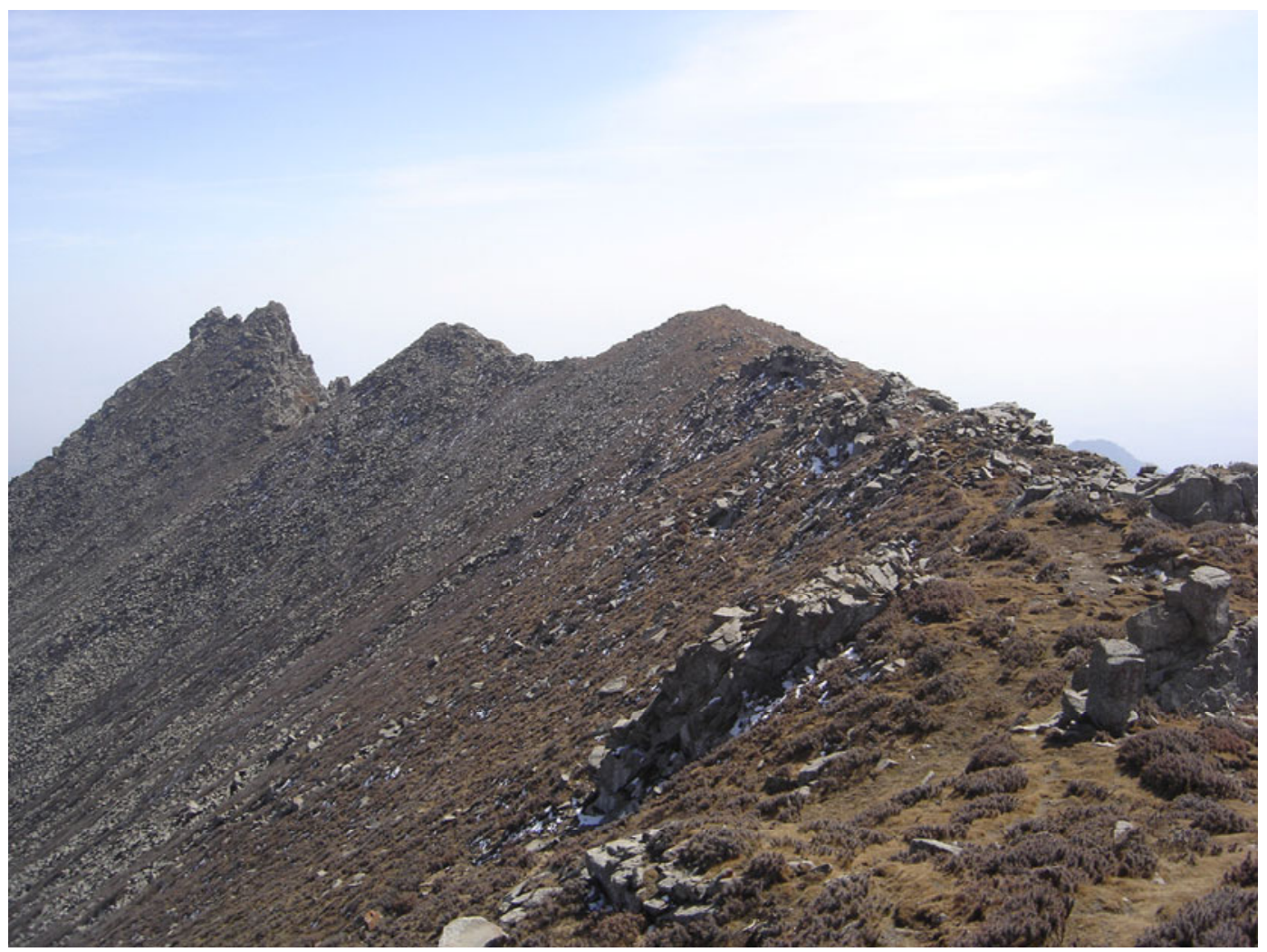

Figure 6 NE glacial ridge developed near the main peak of Helan Mountain. 


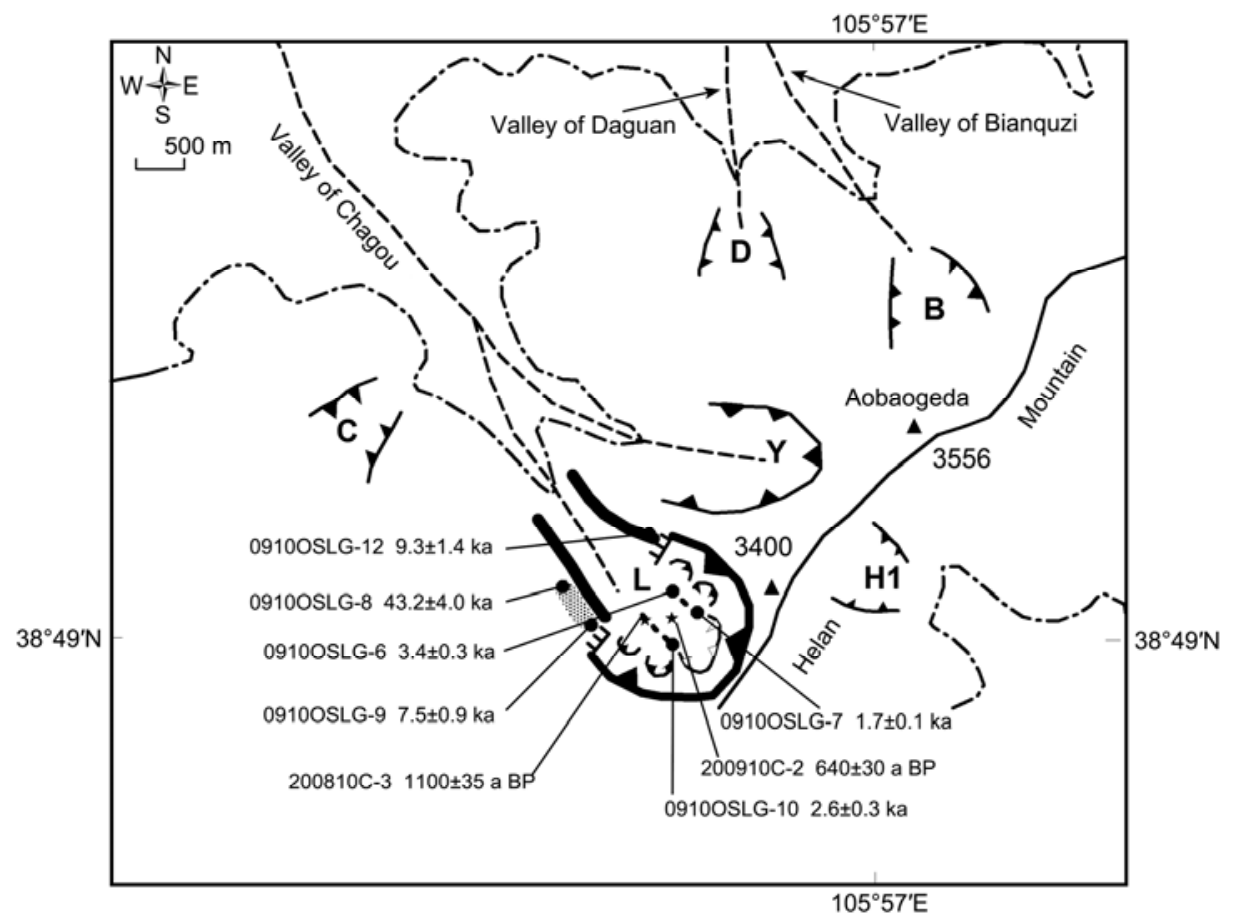

Figure 7 The dating results of glacial events around the peak of Helan Mountain.

already been cut down by the modern flowing water, are the remains induced by the small glacier tongues of the cirques in both sides $\left(Z_{1}, Z_{2}, Z_{3}\right)$ entering into the branch valleys. Length of the moraine located at higher position of $\sim 2860 \mathrm{~m}$ is only about $30 \mathrm{~m}$. This terminal moraine, covered by a $\sim 0.6 \mathrm{~m}$ thick loess layer grown meadow vegetation, is preserved in both sides of the modern river and is $\sim 5 \mathrm{~m}$ higher than the river bed. The exposed profile shows a poorly sorted suspension support texture. The sediments observed in the profile show striated boulders and gravels in a fine sand and silt matrix. The $\sim 0.5-2 \mathrm{~m}$ coarse gravels, accounting for $90 \%-95 \%$ of the sediments, mainly consist of sand-

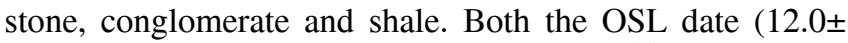
$1.1 \mathrm{ka})$ of the glacial matrixes and the AMS ${ }^{14} \mathrm{C}$ age $(3900 \pm$ 35 a BP) of the soil at the surface of the moraine show this stage glacial advance may have occurred during the late glacial [30]. Located at the position of eastern downstream $(2820 \mathrm{~m})$ of the modern river, extensive deposits caused by the cirque glacier at higher elevation, form a terminal moraine. Based on the morphology and components, this stage glacial advance should be the same as the age of the terminal moraine persevered at $2860 \mathrm{~m}$ (Figure 8). However, two OSL dates of $0.9 \pm 0.1 \mathrm{ka}$ seems very young. The possible reason may be that they have already carelessly been exposed to the sunlight when sampled in the field. In the valley head of Chagou, we did not find the glacial deposits of this stage due to the large-scale loess cover.

(iii) LGM glacial advance. Two asymmetric lateral moraines extending $\sim 1 \mathrm{~km}$ to downstream are persevered in the both sides of the modern river in Chagou. These lateral moraines distribute in the outlet of Lujiatai cirque front at
$3020 \mathrm{~m}$ and extend down to $2800 \mathrm{~m}$. Although the moraines are covered by the spruce and fir, the moraine-like configuration of ridge is clear. The landforms correspond with small convex hill, with higher slope down valley. Higher eastern lateral moraine, $\sim 25 \mathrm{~m}$ above the modern river bed, is $2-4 \mathrm{~m}$ high with steep gradient of $30^{\circ}-40^{\circ}$ inside and gentle gradient of $5^{\circ}-10^{\circ}$ outside. They are distinguishable from the other moraines due to their morphology shape, position and the loess cover. Exposed profile shows that the loess layer covering the diamicts become thinner with the altitude decrease. Located at $\sim 3000 \mathrm{~m}$ position, loess deposit $\sim 350 \mathrm{~m}$ wide, $\sim 100 \mathrm{~m}$ long and $0.5-1 \mathrm{~m}$ thick, called East Platform by local people, is clearly visible on the upper edge of the lateral moraines. Under the loess layer, the deposits in the profile show striated erratic boulders and gravels in a fine sand and silt matrix. The weak weathering coarse gravels (>90\%) usually display polygon shapes such as iron, five angles etc, and mainly consist of sandstone, conglomerate.

Compared with the east lateral moraine, the west lateral $\sim 10 \mathrm{~m}$ above the modern river bed is relatively low and narrow due to irregular fluvial erosion. This lateral moraine connecting with the talus is diamicts sedimentary body, composed of till with abundant angular clasts and superficially covered by large collapse and landslide deposits. In the valley head of Zhaobeishangou, apparent ridge shape landforms develop along the both sides of valley in the eastern $\mathrm{Z}$ cirque. These lateral moraines 400 long, 2-3 m high extend from 2950 to $2850 \mathrm{~m}$. several outcrops show that the sedimentary bodies are composed of purple red shale in the bottom, poorly sorted weak weathering diamicts 


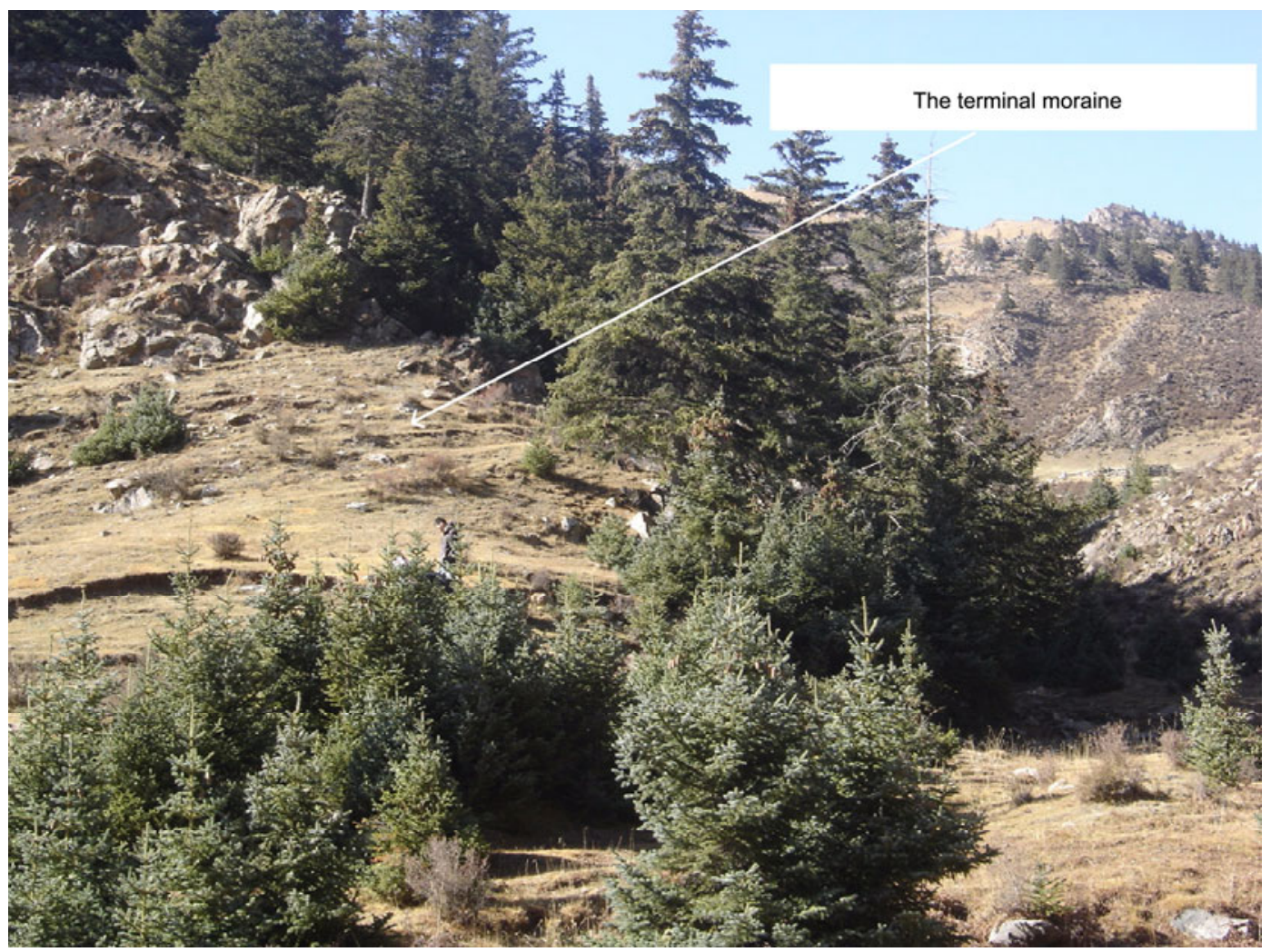

Figure 8 The terminal moraine preserved in the valley of Zhabeishan.

in the middle part, and are covered by $40-60 \mathrm{~cm}$ thick loess deposit. We conclude that formation of the moraines here may be equal to the moraines in the valley head of Chagou. Although the absolute OSL dating is a failure; however, the dated loess ages of $9.3 \pm 1.4 \mathrm{ka}, 6.5 \pm 0.6 \mathrm{ka}, 3.0 \pm 0.3 \mathrm{ka}$ and $4.3 \pm 0.7 \mathrm{ka}$ possibly indicate that this glacial advance might have occurred during the last glacial maximum (LGM).

(iv) Middle stage of last glacial cycle glacier advance. Outside the lateral moraines of LGM, one glacial platform $(3030 \mathrm{~m})$ is preserved close to the outside of glacial threshold in the west of Lujiatai cirque. The $\sim 150$-m-long platform connecting to the talus is $\sim 30$ m higher than the modern river bed. Alpine meadow vegetation such as Caragana and Qinghai shrub cover the deposits. The sediments are composed of till with fewer gravels and abundant fine sand and silt matrix. The contents of fine matrixes obviously increase and account for about $35 \%-40 \%$, and the gravels have already slightly been weathered. According to the morphology position and the composition of sediments, they belong to the remains of another stage glacial advance. The glacial matrixes OSL dates are $43.2 \pm 4.0 \mathrm{ka}$ and $7.5 \pm$ $0.9 \mathrm{ka}$. Based on the glacial deposit sequence and geomorphology relationship, the age of $7.5 \pm 0.9 \mathrm{ka}$, possibly undergoing disturbing after deposition, is not consistent with the geology background. The sedimentary composition and weathering degree indicate that $43.2 \pm 4.0 \mathrm{ka}$ is the true age. This glacial advance may have taken place during the mid- dle stage of last glacial cycle corresponding to the marine isotope stage 3 (MIS 3). In the valley head of Zhaobeishangou, the relics of this glacial stage are not found.

\section{Results and discussion}

\subsection{Glacial sequence accords with the Quaternary glacial pattern in eastern China}

The Helan Mountain is located at a key position for study of past climate and the relationship between glacial action and mountain uplift. Glacial erosive and depositional landforms in the middle part of the Helan Mountain reflect a history of Quaternary glaciation that produced the clear cirques, peaks, knife-edge ridges, lateral moraines, and terminal moraines. The glacial landforms and deposits (Figure 3) show a typical sequence of landscape forming events that took place throughout the Helan Mountain above $2800 \mathrm{~m}$ a.s.l. during the late Quaternary. Geomorphic and relative deposits and absolute ages for the moraines, loess, soil and deposits in the cirque lake in the valley heads of Chagou and Zhaobeishangou provide a primary glacial chronology in this district. We are sure that the glacial advance occurred during the last glacial cycle, which corresponds to the finding that the Quaternary glacial pattern only took place during the last glacial advance in several higher mountains in eastern China $\left(105^{\circ}\right)$ [13]. Field investigation found that glacial 
landforms in the middle stage of last glacial cycle are persevered outside the lateral moraines of LGM and extend discontinuously along the Chagou valley. Destroyed by the mass movement from the steep mountain gradients, the glacial landforms are not complete compared with the moraines of LGM. However, the ridge shape configuration is obvious. The extent of the glacial gravels weathering and the higher contents of fine matrixes show the time of this glacial advance is longer than of the LGM. Meanwhile, the morphology also show that the extent in MIS3 is larger that in LGM.

Adopted $105^{\circ} \mathrm{E}$ as the borderline, Chinese mainland can be divide into modern glaciers existing zone and no modern glaciers zone. The Helan Mountain, higher than $3500 \mathrm{~m}$, is just located at northernmost near the boundary. By comparing the west regions with the east regions, we can discuss the glacial development patterns in different regions. To the west of the Helan Mountain, three glaciations assigned as the Zhonglianggan Glaciation [31], Penultimate Glaciation and Last Glaciation occurred in Lenglongling of the Qilian Mountain (4843 m) and around Bogeda peak (5545 m) in the Tianshan Mountains during the Quaternary epoch. Yi and Zhou [32-35] first reported the older glaciation in the headwater area of the Urumqi River in the Tianshan Mountains and the Bailang River valley in the Qilian Mountain respectively, and its age is 520-405 ka. Recently, Zhao found the evidence of this glacial advance in Tuomuer peak and Ateaoyinake River drainage area of the southern slopes of western Tianshan Mountains (425.3 and 453.0 ka). However, to the east of the Helan Mountain, only glacial remains during the last glacial cycle are persevered in the Changbai Mountains (2691 m) and Taibai Mountain (3767 m) [36-39]. Early Pleistocene glacial advance did not happen in the Tianshan Mountains and Qilian Mountain, while only the last glacial advance occurred in the mountains to the east of the Helan Mountain. According to these evidences, whether there was early Pleistocene glacial advance in the Helan Mountain should be questioned. Further discussion from geomorphology evolution, climate environment and the equilibrium line altitudes are as follows.

\subsection{Uplift history and rates in the Helan Mountain}

The Helan Mountain, adjacent to the Yinchuan graben, transverses the northwest margin of Ordos Basin. It is surrounded by the Bayinhaote Basin and Jilantai Depression developed in the Alashan plate in west and northwest parts. Geological structure and new tectonic movement are complex and extensive. Earth scientists paid wide attention to the differential uplift and descent between the Helan Mountain and Yinchuan Basin, the ages of uplift and the history of geomorphology evolution [11,17,40,41]. According to former study results, the region of the Helan Mountain was aulacogen deposits from middle, late Proterozoic era to early Paleozoic era [42], split-depression occurred during late
Paleozoic era, and this region began to fold and uplift due to the thrust and nappe to the east since middle Cenozoic, and Yinchuan graben extended westward to the margin of the Helan Mountain until the Quaternary. Affected by the India plate diving northward and the stress field induced by the direction change of Pacific plate movement, and especially the compression induced by the Tibetan Plateau uplift, the Helan Mountain was undergoing extensive uplift during the late Pleistocene and formed modern geomorphology pattern at last. Based on the materials of stratum distribution and magma thermal liquid activities, Zhao et al. [17] concluded that minor uplift of the Helan Mountain occurred after the Jurassic Period, large-scale uplift took place in Eocene epoch, and the fast pace uplift started in the Pliocene epoch.

The uplift rates are significantly different depending on the location, calculation method and time range. Yang et al. [41] studied the active faults developed on the alluvial fan in the talus front of the Helan Mountain, combined with the evidence of vertical displacement of $0.95 \mathrm{~m}$ of the Great wall of Ming Dynasty (400 a BP) caused by the faults, and concluded that the rates of the active faults in Holocene was $2.4 \mathrm{~mm} / \mathrm{a}$. Considering both Yinchuan garben and Jilantai Depression belonging to the structural zone of middle axis of mainland, and the west boundary being controlled by the faults of eastern talus of the Helan Mountain, Xu et al. $[43,44]$ inferred that the vertical rate was $1.2 \mathrm{~mm} / \mathrm{a}$ in Holocene. Due to the Yinchuan Basin adjacent to the Helan Mountain, the basin deposit rate can be used as an index of the rate of uplift. Using this method, Kui estimated that the basin deposit rate was about $3.33 \mathrm{~mm} / \mathrm{a}$ in the late Pleistocene [45]. Recently, Zhao et al. [17] estimated the average basin deposit rate during the Quaternary was $0.625 \mathrm{~mm} / \mathrm{a}$ according to the low temperature thermal ages in the Helan Mountain. Adopting the TL dating method, Li et al. studied the terraces of Yellow river near Lanzhou and indicated that Gonghe Movement (150 ka) caused the Longyang Gorge to be incised 900-1000 m [8-10]. If the incised rate equals to the uplift rate of the surrounding mountains, the uplift rate would be $6.0-6.7 \mathrm{~mm} / \mathrm{a}$. Considering the fact that the Helan Mountain is close to the Gonghe Basin in Qinghai Province and that the uplift rates gradually increased during the late Pleistocene, we adopted the relative low uplift rate $\sim 3.5$ $\mathrm{mm} / \mathrm{a}$ as the index to calculate the equilibrium line altitudes in different glacial stages and the mountain uplift rate.

\subsection{Coupled control of uplift and climate on the glaciers development}

(i) Relationship between snowline altitudes and the mountain elevation. Glacier development depends on whether the glacial equilibrium line is higher than the altitude of the mountain. This general law is often applied to studying the relationship between periodical uplift of the Tibetan Plateau and the glacier development. Porter et al. [46] also put forward the same hypothesis when he studied the process of 
glacial action in the Mauna Kea volcano in Hawaii. The method is that the full-glacial (MIS 2) and interglacial snowlines were calculated or determined first, and then the standard marine isotope curve for the past years is placed between these two lines. According to the hypothesis, the standard marine isotope curve is a proxy for global ice volume and is used as a proxy for equilibrium line (ELA) variations under the assumption that the timing and relative amplitude of the isotope peaks approximate the gross fluctuations in ELA. In order to show the coupled control of climate and/or structure on glacier development in the study area, we adopted equilibrium line altitude of last glacial maximum and the modern theoretical snowline altitude as the maximum amplitudes, and the standard marine isotope curve (MIS) as the glacial equilibrium line change since the Gonghe Movement (150 ka) (Figure 9).

Since the Helan Mountain is not covered by glaciers at present, the modern theoretical ELA is calculated using Ohmura's [47] formula and $4274 \mathrm{~m}$ is obtained. Adopting the cirque floor altitudes, maximum elevation of lateral moraines and mean value of terminal to summit altitude methods [48], we determined the ELA in LGM is $3050 \mathrm{~m}$. Considering the uplift rate of $3.5 \mathrm{~mm} / \mathrm{a}$ and the real equilibrium line altitude of $2980 \mathrm{~m}$, we used the mean mountain elevation $\sim 3500 \mathrm{~m}$ as the summit altitude and calculated the mountain elevation during different glacial stages with the same uplift rate. Figure 9 shows that the mean elevation of the Helan Mountain summit $2975 \mathrm{~m}$ before $150 \mathrm{ka}$ was close to the equilibrium line altitude at that time. With the uplift increase, the summit first intersected the snowline curve at the beginning of MIS4.

It is at this time that the mountain reached the altitude and coupled with the glacial climate. So the glacial advance occurred in the early and middle stages of last glacial cycle

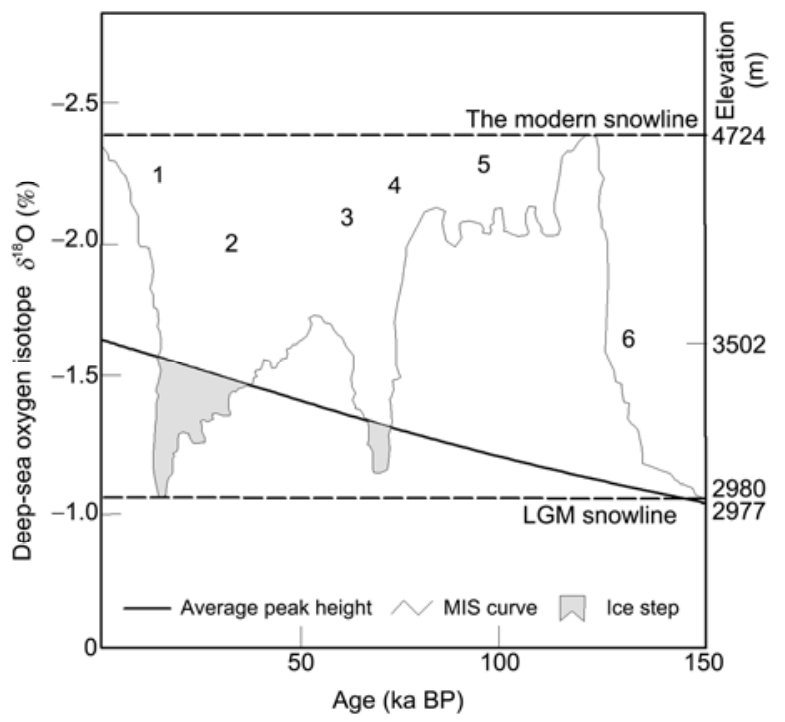

Figure 9 Deep-sea oxygen isotope curve (MIS) and the average peak height variation diagram. after the Gonghe Movement.

(ii) Climate change and the glacier development during the last glacial cycle. Loess-paleosol sequence is widely recognized as one of the best terrestrial Quaternary paleoclimatic records, constituting a nearly continuous terrestrial record of alternating climatic and environmental conditions during the Quaternary. The climate change during glaciation and inter-glaciation can be reflected by the loess-paleosol sequence (Figure 10). Meanwhile, climate change also controls the advance or retreat of the desert and lake. In the west of the Helan Mountain, the Zini Lake is a Quaternary basin in Xilingaole of Inner Mongolia. Shan researched the gully sediments in the north of Xilingaole and found that the profile is mainly composed of lake sediments covered by modern wind sand [49,50]. The sand wedges developed in the upper part of the lake deposit, reflecting clod and dry environment, and indicating that the alternative change of lake and desert in this region during the late Pleistocene. The extensive environmental change is consistent with the last glacial cycle. Moreover, according to the evolution of the Jilantai salt lake, the lake was broken and recessed and the water quality changed to semi-salty. In contrast to the middle and early stages of last glacial cycle, the cold and dry environment was not good to the glacial development during the last glacial cycle [51-55]. In the middle stage of last glacial cycle, especially in MIS3b stage, Ice core of Guliya $[56,57]$ shows the climate was mainly cold and humid and different from the early and late stage of the last glacial cycle. Recent studies found lots of evidence of geomorphology

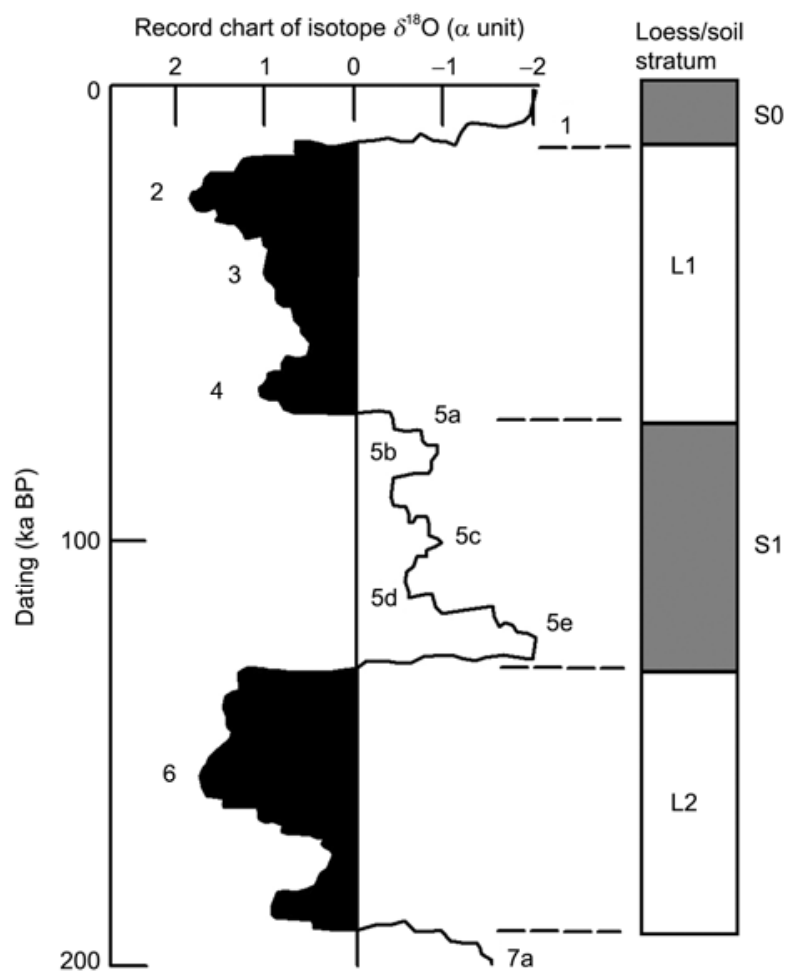

Figure $10200 \mathrm{ka}$ isotope $\delta^{18} \mathrm{O}$ with loess/soil curve modified after [51]. 
and absolute dates about the glacial advance in MIS3b stage in low and middle latitudes [58,59]. All of these indicate that the extensive glacial advance in the Helan Mountain occurred not in global LGM, but in the middle or early stages during the last glacial cycle.

\section{Conclusions}

The glacial landforms and deposits including cirques, peaks, knife-edge ridges, lateral moraines, and terminal moraines distribute above $2800 \mathrm{~m}$ a.s.l. in the middle part of the Helan Mountain. This distribution indicates that here was once glaciated during the late Quaternary and also show a clearly sequence of landscape forming events that took place throughout the Helan Mountain.

The OSL and AMS ${ }^{14} \mathrm{C}$ dating results indicate the late history of glacial advance. Late Pleistocene glaciers in the middle part of the Helan Mountain advanced to near their positions at least four times, and the glacial sequences can be assigned as the middle stage of last glacial cycle (MIS3), last glacial maximum (LGM), late glacial and neo-glacial respectively.

Glacier development in the Helan Mountain during the late Quaternary obviously depended on the coupled control of tectonic uplift of mountain and the climate condition. It is at last glaciation that the mountain reached the altitude above snowline and coupled with the glacial climate. The glacial advance occurred in the early and middle stages of last glacial cycle after the Gonghe Movement.

We thank Zhang Baohong and Wang Zhaoding of Helan Mountain Natural Reserve for helping the field investigation. We also thank the State Key Laboratory of Earthquake Dynamics, Institute of Geology, China Earthquake Administration for its help to perform the OSL dating. We are graceful to the two anonymous refetees for their constructive comments on our manuscript. This work was supported by the National Natural Science Foundation of China (40971010, 40571016).

1 Molnar P, England P. Late Cenozoic uplift of mountain ranges and global climate change: Chicken or egg? Nature, 1990, 346: 29-34

2 Whipple K X, Kirby E, Brocklehurst S H. Geomorphic limits to climate-induced increases in topographic relief. Nature, 1999, 401: 39-43

3 Zhou S Z, Wang X, Wang J, et al. A preliminary on timing of the oldest Pleistocene glaciation in Qinghai-Xizang Plateau. Quat Int, 2006, (154-155): 44-51

4 Shi Y F. Evolution of the cryosphere in the Tibetan Plateau, China, and its relationship with the global change in the Mid Quaternary (in Chinese). J Glaciol Geocryol, 1998, 20: 197-208

5 Cui Z J, Chen Y X, Zhang W, et al. Research history, glacial chronology and origins of Quaternary glaciations in China (in Chinese). Quat Sci, 2011, 31: 1-16

6 Shi Y F, Li J J, Li B Y, et al. Uplift of theQinghai-Xizang (Tibetan) Plateau and East Asia environmental (in Chinese). Acta Geogr Sci, 1999, 54: 10-20

7 Cui Z J, Wu Y Q, Liu G N, et al. On Kunlun-Yellow River tectonic movement. Sci Chin Ser D: Earth Sci, 1998, 41: 592-600

8 Li J J, Fang X M, Ma H Z, et al. Geomorphological and environmen- tal evolution in the upper reaches of the Yellow River during the late Cenozoic. Sci Chin Ser D: Earth Sci, 1996, 26: 316-322

9 Li J J, Fang X M, Pan B T, et al. Late Cenozoic intensive uplift of Qinghai-Xizang Plateau and its impacts on environments in surrounding area (in Chinese). Quat Sci, 2001, 21: 381-391

10 Li J J, Fang X M. Uplift of the Tibetan Plateau and environmental changes (in Chinese). Chin Sci Bull (Chin ver), 1999, 43: 1569-1574

11 Shan P F, Wen J L, Qu X N. An approach to the characteristics of neo-tectonic movement in the eastern foot of Helan Mt. (in Chinese). Arid Land Geogr, 1991, 14: 15-20

12 Hofumann J. Investigation of present and former periglacial, nival glacial features in Central Helan Shan (Inner Mongolia/the People's Rep. of China). Z Geomorph N F. 1992, 86(suppi-Bd): 139-154

13 Li J J. Glacial relics of monsoonal Asia in the last glaciation (in Chinese). Quat Sci, 1992, 4: 42-48

14 Wang X Y. Glacial vestiges in the western foreland of Helan Mountain. J Geol Soc Ningxia, 1983, 4: 42-48

15 Wang X Y. Quaternary glacial vestiges in the western foreland of Helan Mountain. Geol Min Res, 1988, 20: 149-155

16 Groups of Quaternary Glaciers of Helan Mountain in Ningxia. A study on the Quaternary paleoglaciers and its significance in Helan Mountain. J Ningxia Univ, 1993, 14: 80-83

17 Zhao H G, Liu C Y, Wang F, et al. Constraints the uplift age of Helan Mountain and its evolutionary. Sci Chin Ser D: Earth Sci, 2007, 37: $185-192$

18 Geng K, Yang Z R. Climatic characteristics and climatic landforms in Helan Mountain (in Chinese). Yantai Teachers' College J, 1990, 6: 49-56

19 Cui Z J, Yang C F, Liu G N, et al. The Quaternary glaciation of Shesan Mountain in Taiwan and glacial classification in monsoon areas. Quat Int, 2002, (97-98): 147-153

20 Zhang W, Cui Z J, Feng J L, et al. Late Pleistocene glaciation of the Hulifang massif of Gongwang Mountains. J Geogr Sci, 2005, 4: $448-458$

21 Yi C L, Liu K X, Cui Z J. AMS dating on glacial tills at the source area of Ürümi River in the Tianshan Mountains and its implications (in Chinese). Chin Sci Bull (Chin ver), 1998, 43: 655-656

22 Zhou S Z, Xu L B, Colgan Patrick M, et al.Cosmogenic ${ }^{10}$ Be dating of Guxiang and Baiyu glaciations. Chin Sci Bull, 2007, 52: 1387-1393

23 Cui Z J, Yang J F, Liu G N, et al. Discovery of Quaternary glacial evidence on Shesan Mountain in Taiwan, China. Chin Sci Bull, 2000, 45: 566-571

24 Clarke M L, Rendell H M, Wintle A G. Quality assurance in luminescence dating. Geomorphology, 1999, 29: 173-185

25 Richards B W, Owen L A, Rhodes E J. Timing of late Quaternary glaciations in the Himalayas of northern Pakistan. J Quat Sci, 2000, 15: 283-297

26 Wang X L, Lu Y C, Li X N. Luminescence dating of fine-grained quartz in Chinese loess-simplified multiple aliquot regenerativedose(MAR) protocol (in Chinese). Seismol Geol, 2005, 27: 615-623

27 Lu Y C, Wang X L, Wintle A G. A new OSL chronology for dust accumulation in the last $130000 \mathrm{yr}$ for the Chinese Loess Plateau. Quat Res, 2007, 1: 152-160

28 Wang T L, Chen J, Yang C C. Calibration of daybreak thick source alpha counter and preliminary study of influencing factors (in Chinese). Seismol Geol, 2005, 4: 633-644

29 Aitken M J. An Introduction to Optical Dating: The Dating of Quaternary Sediments by the Use of Photon-stimulated Luminescence. Oxford: Oxford University Press, 1998. 216-239

30 Zhao J D, Shi Y F, Wang J. Comparison between Quaternary glaciations in China and the marine oxygen isotope stage (MIS): An improved schema (in Chinese). Acta Geogr Sci, 2011, 66: 866-884

31 Zhou S Z, Li J J, Zhang S Q, et al. Glacial geomorphology and ice ages in the Bailang River basin, Qilian Mountain (in Chinese). J Glaciol Geocryol, 2001, 23: 131-138

32 Zhao J D, Liu S Y, He Y Q, et al. Quaternary glacialchronology of the Ateaoyinake River valley, Tianshan Mountains, China. Geomorphology, 2009, 103: 276-284

33 Zhou S Z, Li J J, Zhang S Q. Quaternary glaciation of the Bailang 
River valley, Qilian Shan. Quat Int, 2002, 97-98: 103-110

34 Zhao J D, Zhou S Z, He Y Q, et al. ESR dating of glacial tills and glaciations in the Urumqi River headwaters, Tianshan Mountains, China. Quat Int, 2006, 144: 61-67

35 Zhao J D, Wang J, Shangguan D H. Sequences of the Quaternary glacial sediments and their preparatory chronology in the Tomur River valley, Tianshan Mountains (in Chinese). J Glaciol Geocryol, 2009, 31: 628-633

36 Zhang W, Yan L, Cui Z J, et al. Present and late Pleistocene equilibrium line altitudes in Changbai Shan, northeast China (in Chinese). Quat Sci, 2008, 28: 739-745

37 Zhang W, Niu Y B, Yan L, et al. Late Pleistocene glaciations of Changbai Mountains in northeastern China. Chin Sci Bull, 2008, 53: 2672-2684

38 Tian Z S, Huang C C. The glaciation process in Mt. Taibai of the Qinling Mountains and the climatic changes in the Loess Plateau (in Chinese). Geogr Res, 1990, 9: 15-23

39 Liu G N, Fu H R, Cui Z J, et al. An 8000 years environmental change record of lacustrine deposits of Foyechi lake at Taibai Mountains (in Chinese). Res Soil Water Conserv, 2005, 12: 1-4

40 Zhang J, Ma Z J, Ren W J. Re-discussion on natures of extension in Helanshan region before Cenozoic era (in Chinese). Acta Petrol Sin, 2004, 25: 8-11,17

41 Yang J C, Guo Z T, Cao J D. Investigation on the Holocene activities of the Helan Mountain piedmont fault by use of geomorphological method (in Chinese). Seismol Geol, 1985, 7: 23-31

42 Shan P F. New tectonic movements and environmental evolution in the Helan Mountain. Quaternary Glaciers and Environment in West China. Beijing: Science Press, 1990. 299-304

43 Xu X W, Yu G H, Ma W T, et al. Model of latest crustal tectonic motion of the central tectonic zone on the mainland of China (in Chinese). Earth Sci Front, 2003, 10: 160-167

44 The Research Group on Active Fault System Around Ordos Massif, State Seismological Bureau. Active Fault System Around Ordos Massif (in Chinese). Beijing: Seismological Press, 1988. 1-335

45 Kui F P. Appearances of the tectonic movements and its dynamics processes during the Cenozoic in Ningxia. Ningxia. In: Proceeding of Seismology and Geology. Tianjin: Science and Technology Publisher of Tianjin, 1986. 1-217

46 Porter S C. Pleistocene snowlines and glaciation of Hawaiian Islands. Quat Int, 2005, 138/139: 118-128

47 Ohmura A, Kasser P, Funk M. Climate at the equilibrium line of glaciers. J Glaciol, 1992, 38: 397-411

48 Benn D I, Lehmkuhl F. Mass balance and equilibrium-line altitudes of glaciers in high-mountain environments. Quat Int, 2000, 65-66: 15-29

49 Shan P F. Periglacial landform process and its environmental changes in the Zinihu region at the western side of the Helan Mountain since the late Pleistocene (in Chinese). Geol Rev, 1997, 43: 428-433

50 Shan P F. Discovery of the ice wedges during the last glacial cycle in the northeast margin of Tenggeli Desert and its significanc (in Chinese). Chin Sci Bull (Chin ver), 1996, 41: 160-163

51 Rost K T. Pleistocene paleoenvironmental changes in the high mountain ranges of central China and adjacent regions. Quat Int, 2000, 65/66: 147-160

52 Guo Z T, Peng S Z, Wei L Y, et al. Millennial-scale oscillations of the East-Asian summer monsoon over the last $0.220 \mathrm{Ma}$ (in Chinese). Quat Sci, 1999, 4: 299-303

53 An Z S, Poter S C. Millennial-scale climate oscillations during the last interglaciation in central China. Geology, 1997, 25: 603-606

54 Su D H, Wu X H, Liu D S. Evolution of the summer monsoon regime over the loess plateau of the last $150 \mathrm{ka}$. Sci Chin Ser D: Earth Sci, 1996, 39: 503-511

55 Rost K T. Plaeo-climatic field studies in and along the Qinling Shan (central China). GeoJournal, 1994, 34: 107-120

56 Yao T D, Thompson L G, Shi Y F, et al. Climate variation since the Last Interglaciation recorded in the Guliya ice core (in Chinese). Sci China Ser D: Earth Sci, 1997, 27: 447-452

57 Wu G J, Yao T D, Thompson L G, et al. Microparticle record in the Guliya ice core and its comparison with polar records since the last interglacial (in Chinese). Chin Sci Bull (Chin ver), 2004, 49: 475-479

58 Shi Y F, Yao T D. MIS 3b (54-44 ka BP) cold period and glacial advance in middle and low latitudes (in Chinese). J Glaciol Geocryol, 2002, 24: 1-9

59 Wang J. Glacial advance in the Qinghai-Tibet Plateau and peripheral mountains during the mid-MIS 3 (in Chinese). Quat Sci, 2010, 30: $1055-1065$

Open Access This article is distributed under the terms of the Creative Commons Attribution License which permits any use, distribution, and reproduction in any medium, provided the original author(s) and source are credited. 